\title{
COVID-19 impacts on Disability and Rehabilitation in Bangladesh
}

\author{
Sharmin Alam ${ }^{*}$ (D), S.M. Yasir Arafat ${ }^{2}$ iD, KM Amran Hossain ${ }^{3}$ (D) Mohamed Sakel $^{4}$ (D) \\ ${ }^{1}$ Centre for the Rehabilitation of the Paralysed (CRP), Dhaka-1343, Bangladesh \\ ${ }^{2}$ Department of Psychiatry, Enam Medical College Hospital, Dhaka, Bangladesh \\ ${ }^{3}$ Department of Physiotherapy, Bangladesh Health professions Institute, Dhaka, Bangladesh \\ ${ }^{4}$ Director Neuro-Rehabilitation, East Kent University NHS FT Hospitals, UK
}

\begin{tabular}{|lrr|}
\hline Article ID: BPJ/10/01/02 & DOI: 10.46945/bpj.10.1.02 \\
Received: June 4, 2020 & Accepted: August 28, 2020 & Published: September 1, 2020 \\
\hline
\end{tabular}

\begin{abstract}
Bangladesh is going through a potentially catastrophic situation during the COVID-19 pandemic. The most densely populated country in the world with a high rate of disabled people, poor economic resilience, and lack of proper pandemic preparedness makes it particularly vulnerable. Rehabilitation care for disabled people will fare even worse fate during this pandemic unless a clear national strategy is formulated rapidly, which must be implemented quickly. The paper aims to explain the impact of COVID 19 on the Persons with disability of Bangladesh in epidemiological, healthcare, social and rehabilitation contexts.
\end{abstract}

Keywords: SARS CoV 2, Disability, Rehabilitation, Bangladesh

\section{Background}

World Health Organization declared SARS CoV2 or Coronavirus Disease 19 as a global pandemic and alarmed the lower-middle-income countries to have a greater risk of transmission ${ }^{[1]}$ Bangladesh confirmed the first case on March 7, 2020 ${ }^{[2]}$; Government reports 156,362 cases have been diagnosed with COVID-19, among them 68,048 cases cured (43.5\%) and 1,968 deaths (1.3\%) till July 4, 2020. ${ }^{[3]}$ The country also reported the first case of a child who died aged six years on April 13 in Chottogram. She was a physically challenged child with cerebral palsy. ${ }^{[4]}$ Bangladesh has nearly $10-15 \%$ of people with disabilities and $80 \%$ of them living in rural areas ${ }^{[5]}$, and disability has been defined by Persons with disabilities rights and protection Act (2013) and neurodevelopmental disability protection trust act (2013) as physical, psychological, visual, speech, intellectual, hearing, cerebral palsy, autism spectrum disorder, and down's syndrome. For many reasons, the persons with disabilities (PWD's) and the frontline rehabilitation practitioners of Bangladesh are at higher risk of COVID-19 in Bangladesh.

\section{Perspectives}

From the epidemiological perspective, there is no estimation of PWDs infected by SARS CoV-2 and reported inaccessibility of healthcare towards them. One study disclosed that about $50 \%$ of the population with neurological disabilities has the inability of accessing health and rehabilitation care due to inaccessibility in travelling to the centre, poor economic condition, and lack of awareness; It takes six months to 2 years to access healthcare for a PWD's
${ }^{[6]}$ and there is a common determination that the PWDs will face numerous challenges to attend the test centres as maximum test centre are situated in the divisional cities and urban area.

From the healthcare perspective, PWD's have pre-existing risk and comorbidities. World Health Organization (2020) illustrate some factors related to the pre-existing risk of COVID-19 infection towards PWDs as, difficulty maintaining hygiene such as hand-washing because of physical difficulties or inaccessibility, dependency on the caregiver, difficulties in maintaining social distancing, poor physical functioning, and mental health, and comorbidity of poor respiratory fitness. ${ }^{[7]}$ A population-based study suggests $62 \%$ of the cerebral palsy child have associated risk factors as pneumonia, sepsis, CNS infection, meningitis, or encephalitis in Bangladesh. ${ }^{[8]}$ Another study suggests $65 \%$ of rehabilitated Spinal Cord injury people in the community are dependent on the caregiver, and $75 \%$ of them experienced respiratory, Integumentary, or other infective conditions in the last two years. ${ }^{[9]}$ These pre-existing health issues imply serious complications due to unavailability of health care services and rights, lack of support, consideration as disposable causalities, and absence in policy for the PWDs; and multiplies the risks to the COVID-19. ${ }^{[10]}$ Bangladesh is reported to have such inequities, and the burden is multiplying with female gender, child, homeless, and refugees. ${ }^{[11]}$ 
In the Communication and Social perspective, there is inaccessibility of adequate information and resources regarding SARS CoV 2 for PWD's. In Bangladesh, a larger number of congenital disabilities are the illiterate and similar portion of acquired disabilities unable to read and understand complex articles ${ }^{[10]}$ and finding hurdles to understanding and maintain safety measures whereas the digital content, internet, and website are not easily accessible and obtainable for PWDs.

And in the Rehabilitation perspective, Bangladesh has no protective policy for the rehabilitation workforce or involvement of Rehabilitation professionals in the frontline workforce. ${ }^{[12]}$ Evidence and best practice guidelines recommend to involve physiotherapy and rehabilitation professionals in acute COVID-19 healthcare settings with adequate personal protective equipment (PPE) ${ }^{[13]}$ and also suggested to continue the rehabilitation services online as the telemedicine facility. Studies reflect the scarcity of PPE in emergency care ${ }^{[14]}$. Also, there are reports of the inaccessibility of PPE for rehabilitation care settings. ${ }^{[15]}$ In low affluent countries, PWDs and families are encouraged to continue Community based rehabilitation and accessing care through online consultation ${ }^{[13]}$. Bangladesh has no available data regarding how many of PWD's have access to the internet and video calling and how much this is accessible to them.

\section{Recommendations}

The PWD's our country's largest minority, and the impact is significant. In epidemiological prospect, enlistment of PWD's and families affected by COVID 19 needs to be estimated integrating with national disability database, and impose policy to reach the testing facilities to the PWD's and vulnerable population in Bangladesh. As per healthcare perspectives, the disability considerations for COVID-19 ${ }^{[7]}$ need to be implemented, and dedicated facilities are encouraged. Alternative and augmented communication (AAC) are recommended to employ in case of every publication and advisory of COVID-19 to remove the cognitive barrier. And to ensure effective and sustainable Rehabilitation services, the involvement of Multidisciplinary workforce in COVID 19 frontline, ensure adequate protective measures to health and rehabilitation workforce and encourage innovative telerehabilitation technologies accessible for PWD's are strongly recommended. Bangladesh has a separate allocation of business between the Ministry of Health and Ministry of Social welfare regarding PWD's ${ }^{[6]}$; hence comprehensive measures are also recommended.

\section{Conclusion}

Bangladesh is going through a potentially catastrophic situation during the COVID-19 pandemic. The most densely populated country in the world with a high rate of disabled people, poor economic resilience, and lack of proper pandemic preparedness makes it particularly vulnerable. Rehabilitation care for disabled people will fare even worse fate during this pandemic unless a clear national strategy is formulated, which must be implemented quickly.

Competing Interest: Authors declare no conflict of interest. *Correspondence: Pediatric Rehabilitation Unit, Centre for the Rehabilitation of the Paralysed (CRP), Dhaka-1343, Bangladesh, email: sharminalam980@gmail.com

\section{References}

1. WHO (2020). COVID 19. Available at: <https://www.who.int/southeastasia/outbreaks-andemergencies/novel-coronavirus-2019> [Accessed 26 April 2020].

2. Anwar, S., Nasrullah, M., \& Hosen, M. J. (2020). COVID19 and Bangladesh: Challenges and How to Address Them. Front. Public Health, 8, 154.

3. Combined Government reporting website (2020) Available at https://corona.gov.bd/graph [Accessed July 4 2020].

4. The Business Standard (2020). Chattogram reports first child death from coronavirus. Available at: https://tbsnews.net/coronavirus-chronicle/covid-19-

bangladesh/chattogram-reports-first-child-deathcoronavirus-68458 [Accessed 10th May 2020]

5. Worldbank.org. (2020). Available at:

<http://siteresources.worldbank.org/DISABILITY/Resource s/Regions/South\%20Asia/DisabilityinBangladesh.pdf>

[Accessed 29 April 2020].

6. Wesley, P., Rajib, H., Manjula, M., Liem, N., Fleur, S., Ahmed, J. F., Golam, M. (2019). Coordination between health and rehabilitation services in Bangladesh: Findings from 3 related studies. Handicap International (Humanity and Inclusion), Dhaka. Available at:

https://asksource.info/resources/coordination-betweenhealth-and-rehabilitation-services-bangladesh-findings-3related [Accessed 10th may 2020]

7. WHO (2020). Disability considerations during the COVID-19 outbreak. Available at:

https://www.who.int/publications/i/item/disabilityconsiderations-during-the-covid-19-outbreak [Accessed July 4 2020]

8. Khandaker, G., Muhit, M., Karim, T., Smithers-Sheedy, H., Novak, I., Jones, C., \& Badawi, N. (2019).

Epidemiology of cerebral palsy in Bangladesh: a populationbased surveillance study. Developmental Medicine \& Child Neurology, 61(5), 601-609.

9. Hossain, M. S., Rahman, M. A., Bowden, J. L., Quadir, M. M., Herbert, R. D., \& Harvey, L. A. (2016).

Psychological and socioeconomic status, complications and quality of life in people with spinal cord injuries after 
discharge from hospital in Bangladesh: a cohort study. Spinal Cord, 54(6), 483-489.

10. Thelwall, M., \& Levitt, J. M. (2020). Retweeting Covid19 disability issues: Risks, support and outrage. $E l$ profesional de la información (EPI), 29(2).

11. Tareque, M. I., Begum, S., \& Saito, Y. (2014). Inequality in disability in Bangladesh. PLoS One, 9(7).

12. Director General of Health Services (2020). Medical Team. Available at: http://103.247.238.92/webportal/pages/covid19.php

[Accessed July 4 2020]

13. Thomas, P., Baldwin, C., Bissett, B., Boden, I.,

Gosselink, R., Granger, C. L., \& Ntoumenopoulos, G.
(2020). Physiotherapy management for COVID-19 in the acute hospital setting: clinical practice recommendations. Journal of Physiotherapy, 6 (2), April 2020, 73-82 doi.org/10.1016/j.jphys.2020.03.011

14. Bodrud-Doza M, Shammi M, Bahlman L, Islam ARMT and Rahman MM (2020) Psychosocial and Socio-Economic Crisis in Bangladesh Due to COVID-19 Pandemic: A Perception-Based Assessment. Front. Public Health 8:341. doi: 10.3389/fpubh.2020.00341

15. Jamuna Television (2020). Paralyzed Patient are being treated without PPE at CRP. Available at: https://www.youtube.com/watch?v=kUAtUeRJ_n0 [Accessed 10 ${ }^{\text {th }}$ May 2020]

Copyright (C2020 Sharmin Alam et al. This article is distributed under the terms of Creative Commons Attribution License which permits unrestricted use, distribution and reproduction in any medium provided the original author(s) and original publisher are properly credited. 